\title{
Mindsets of Native Japanese Speakers When Interacting with Non-Native Speakers: Using Semi-Structured Interviews
}

\author{
Koichi Shimahara \\ Rikkyo University, Tokyo, Japan
}

How to cite this paper: Shimahara, $\mathrm{K}$. (2018). Mindsets of Native Japanese Speakers When Interacting with Non-Native Speakers: Using Semi-Structured Interviews. The Educational Review, USA, 2(3), 209-216. http://dx.doi.org/10.26855/er.2018.03.002

Corresponding author: Koichi Shimahara, Ph. D., Rikkyo University, Tokyo, Japan.

\begin{abstract}
With the number of non-native speakers of Japanese increasing in Japan, some researchers have claimed that Japanese as a lingua franca (JLF). If JLF comes to be used in Japanese society and learned by native speakers, not only should their linguistic features be analyzed, but also their mindsets, with special focus on how they change. This study aims to reveal the mindsets of native Japanese speakers when interacting with non-native Japanese speakers and what factors can affect them. To achieve this, semi-structured interviews were conducted with eight native speakers where they were questioned about their past experiences with non-native speakers. The application of follow-up interviews as the research method allowed changes in those mindsets to be revealed. As a result, mindsets mentioned in interviews were categorized into three groups - taking care to speak intelligibly, wanting to improve their interlocutors' Japanese language skills, and wanting to continue the conversation. Presenting actual narratives within each category should be valuable for future research. Moreover, three factors that seem to influence those mindsets were presented-experience interacting with non-native speakers, experience as non-native English speakers, and experience taking Japanese language teaching coursework.
\end{abstract}

\section{Keywords}

Native Japanese Speakers, Non-Native Speakers, Semi-Structured Interviews

\section{Introduction}

With the number of non-native speakers of Japanese increasing in Japan, some researchers have claimed that Japanese as a lingua franca (JLF), or Japanese as spoken by non-native speakers of Japanese, has different norms from Japanese as used by native speakers (Okazaki 2000, etc.). Therefore, they argue, it is necessary for native Japanese speakers to be aware that the norms of Japanese language usage in conversations between native speakers differ from those in conversations between native and non-native speakers. In theory, the acceptance of JLF in conversations means the Japanese language is no longer inherent to native Japanese speakers, and the distinction between the communication of native versus non-native speakers breaks down. In that case, there would be no power balance issues between them in interactions, issues which have often pointed out in past research. In addition, using JLF could lead to equal participation from and an equal relationship between both speakers in an interaction, regardless of their linguistic background. Okazaki (2002) states that "they (native speakers and non-native speakers) are completely equal in theory in that both are learners of JLF". Following these researchers, the Ministry of Internal Affairs and Communications has proposed such an equal 
relationship between native and non-native speakers to be ideal in the coming multicultural society in Japan. Therefore, non-native speakers should not receive any disadvantages merely because their mother tongues are not Japanese.

If JLF becomes the most common language used in conversations between native and non-native speakers in the coming multicultural society, both types of speakers might be required to learn it. However, we currently do not have a clear idea of how native speakers acquire JLF. A study conducted by Yanagida (2011) analyzed how native speakers' linguistic features change as they interact with non-native speakers over a long period. However, their mindsets-i.e., what they pay attention to during conversations - have rarely been the focus of empirical research. If JLF comes to be used in Japanese society and learned by native speakers, not only should their linguistic features be analyzed, but also their mindsets, with special focus on how they change.

In previous research, native speakers' mindsets were analyzed mostly in follow-up interviews, which are interviews conducted after conversations have taken place (Tsuda 2003, etc.). Through follow-up interviews, each utterance expressed in actual conversations can be scrutinized with very specific questions: for example, "Why did you talk like this?" and "What made you say this sentence?" However, what can be analyzed by follow-up interviews is only what participants pay attention to during the conversations; how their mindsets change cannot be determined.

This study aims to reveal the mindsets of native Japanese speakers when interacting with non-native Japanese speakers and what factors can affect them. To achieve this, semi-structured interviews were conducted with eight native speakers where they were questioned about their past experiences with non-native speakers. The application of a semi-structured interview format was expected to be able to reveal how their mindsets change and what factors influence those changes.

In the next chapter, the methodology of this research will be described in detail.

\section{Methodology}

Semi-structured interviews were conducted with eight native Japanese speakers to reveal what mindsets they have and what factors have influenced them. Because one's mindset during a conversation is at times very personal, establishing a good rapport with interviewees is an important aspect of data collection when using this methodology. In order to facilitate the development of good rapport, the participants were selected through snowball sampling. Under this process, each interviewee was asked to introduce another candidate interviewee who had previously interacted more with non-native speakers. Milroy and Gordon (2003) described this sampling method as advantageous for allowing "a new subject not as a complete outsider but more in the role of a "friend of a friend"' (p. 32) to become a part of the study.

Basic information on the eight interviewees is presented below.

Table1. Basic information of interviewees.

\begin{tabular}{|c|c|c|c|}
\hline Name & Age & Sex & Main Experiences with Non-Native Speakers \\
\hline Iwata & 21 & Female & $\begin{array}{l}1 \text { year study abroad in Australia, } \\
\text { International Activity Circle at university }\end{array}$ \\
\hline Itai & 22 & Female & $\begin{array}{l}1 \text { month study abroad in United States, } \\
\text { International activity circle at university }\end{array}$ \\
\hline Ichimaru & 27 & Female & $\begin{array}{l}1 \text { year study abroad in United States, } \\
\text { Tutor experience at international dormitory }\end{array}$ \\
\hline Komoto & 22 & Male & Friends at university \\
\hline Sasaki & 22 & Female & $\begin{array}{l}\text { Friends at university } \\
\text { Japanese language teaching training }\end{array}$ \\
\hline $\begin{array}{l}\text { Kaji } \\
\text { Saika }\end{array}$ & $\begin{array}{l}25 \\
22\end{array}$ & $\begin{array}{l}\text { Male } \\
\text { Female }\end{array}$ & $\begin{array}{l}\text { Japanese language teaching training } \\
\text { Japanese language teaching training }\end{array}$ \\
\hline Suzuhara & 22 & Female & $\begin{array}{l}\text { Friends at university, } \\
\text { Japanese language teaching training }\end{array}$ \\
\hline
\end{tabular}


In the semi-structured interviews, questions similar to the ones below were used to reveal participants' mindsets during conversations.

- Do you remember when you talked with non-native speakers of Japanese for the first time in your life? Please describe the situation and what you thought during or after the conversation.

- In your school (elementary school, junior high school, high school, university, etc.) days, did you have a chance to talk with non-native Japanese speakers, regardless of which language you used? Please describe each situation in detail and what you thought or noticed during each conversation.

- Do you have any memorable moments from interactions with non-native speakers? Please describe them.

- Do you have any experience as a non-native speaker of any language? If you have, please describe each interaction, each speaker, and what you noticed during each interaction.

- What do you usually pay attention to during conversations with non-native Japanese speakers? Do you think your mindset changes according to the situation and the speakers? If so, please mention a few examples from your experience.

- What kind of difficulties do you think non-native speakers of Japanese have during conversations with native speakers? Have you taken specific actions to reduce those difficulties for them?

Semi-structured interviews were conducted with each interviewee from May to July in 2014. Each interview lasted sixty minutes and was conducted twice with each interviewee in order to establish good rapport. For the analysis, all sound data was transcribed with phonetic information. The transcription was coded and categorized, focusing on what interviewees paid attention to during conversations and the factors thought to have influenced their mindsets.

Although its ability to reveal changes in interviewees' mindsets could be stated to be an advantage of the semi-structured interview methodology, some possible disadvantages should also be mentioned here. First, although the interviewer gave participants enough time to remember each conversation and to answer each question, it is still possible for them to have not accurately remembered their previous mindsets. Second, because only what can be put into words can be expressed in interviews, there could have been other, untold elements that influenced their mindsets.

\section{Findings}

Using qualitative analysis, the researcher categorized the mindsets expressed by participants in the interviews into three groups: taking care to speak intelligibly, wanting to improve their interlocutors' Japanese language skills, and wanting to continue the conversation. After looking at these categories within the context of actual narratives, we present three factors which seem to influence their mindsets.

\subsection{Three Categories of Mindsets}

\subsubsection{Taking Care to Speak Intelligibly}

All of the native speakers reported they take care to speak intelligibly when they talk with non-native speakers. Related linguistic and para-linguistic behaviours mentioned in interviews were to speak slowly, to speak with short and simple sentences, and to not use difficult vocabulary. Below is a quote from Itai.

1) I speak slowly and clearly: otherwise, they wouldn't understand.

(from Itai)

Quote 1 was the most common characteristic of the mindsets of the interviewees, especially in their conversations with non-native speakers with limited Japanese proficiency. However, even in conversations with those with high Japanese proficiency, some native speakers expressed that they still take care to speak intelligibly. Below is another quote from Itai. 
2) I don't know why, but I did speak slowly with a German friend. His Japanese was exceptionally good and I'm sure he would have understood what I meant even if I didn't speak slowly. But still, I did speak slowly with him.

(from Itai)

Past research on foreigner talk - defined as "the particular register used primarily to address foreigners: i.e, people who do not have full native competence in one's language" (Ferguson 1981, p.10) — has revealed that non-native speakers of a language, especially those with high proficiency in it, often negatively evaluate foreigner talk by native speakers, including behaviours such as speaking slowly and using basic vocabulary (Sakamoto et al. 1989). Although Itai stated her German friend did not comment about the way she spoke, it is possible that he evaluated it negatively. As for the changes in the way they speak, most native speakers expressed that they were able to speak slowly and clearly from the beginning of their recollections, even in their elementary school days. However, they also mentioned that the way in which they choose words and adjust sentences has changed, attributing this to various factors. Quote 3 is from Komoto.

3) I could speak slowly and clearly from the beginning, but I came to be able to choose my words and adjust my sentences through the experience of interactions with non-native speakers.

(from Komoto)

Some native speakers actually reported being able to choose their words and adjust their sentences according to their interlocutors. However, it is thought to be difficult for native speakers to judge which words are easy or difficult for non-native speakers to understand. The next quote was Itai's answer to the question, "How do you judge which words are easy or difficult?"

4) Since they would understand what primary Japanese school kids use, I used those words.

(from Itai)

Some research has revealed differences between the ways native and non-native speakers perceive the difficulty of vocabulary. What participants report in interviews and what they actually do can be different. Whether or not Itai could actually speak clearly and choose her words and sentences carefully cannot be proven based on self-reporting alone: therefore, actual conversations with her as an interlocutor would need to be analysed.

In addition to interactions with non-native speakers, Japanese language teaching coursework was also mentioned in interviews as a factor influencing speech patterns. The quote below is from Sasaki.

5) I know how I can speak Japanese intelligibly because my major is Japanese Language Teaching. If it were not, my speech would likely be naturally more difficult for non-native speakers to understand.

(from Sasaki)

Here in quote 5, Sasaki reported how she became able to choose her words and sentences according to her listener's Japanese proficiency. Because her major is Japanese Language Teaching, she felt very confident to judge her interlocutors' proficiency in Japanese and to adjust her vocabulary appropriately.

In summary, for the factor "Taking care to speak intelligibly", two factors influencing participants' mindsets and the way they speak were revealed: experience interacting with non-native speakers and experience taking Japanese language teaching coursework.

\subsubsection{Wanting to Improve Their Interlocutors' Japanese Language Skills}

Some native speakers reported that they wanted to improve their interlocutors' Japanese language skills. The Jap anese language has two main speech styles, polite style and plain style, the difference between which "has traditionally been described as the distinction between formality and informality respectively" (Miyamoto, 2008, p.132). Re- 
lated linguistic behaviours mentioned in interviews were to correct mistakes actively and to use slang and plain style. A quote below refers to correcting mistakes.

6) I always correct their mistakes because I'm sure every international student wants to improve their Japanese.

(from Iwata)

All native speakers in this study were university students. Therefore, most of the non-native speakers mentioned by native speakers were international students attending university. Because most international students enrolled in Japanese universities are thought to study Japanese, it might be true that they "want to improve their Japanese". However, whether or not they want to learn through daily conversations is questionable. Some non-native speakers might not be willing to recognize and accept their mistakes in daily conversations. Moreover, correcting mistakes is often pointed out to be a negative face violation of the hearer from the perspective of Brown \& Levinson's politeness theory (1987). It could be claimed that too many corrections in conversations can lead to interpersonal problems. Mindsets regarding slang and plain style are depicted by the quotes below from Iwata.

7) I use slang actively because international students wouldn't know it unless they use slang with friends, and that's how I learned English slang.

(from Iwata)

8) I always use plain style with them because I guess they usually use polite style in classrooms or with teachers.

(from Iwata)

In quote 7, the influence of Iwata's experience as a non-native English speaker was explicitly mentioned. Iwata emphasized her experience studying abroad for a year throughout the interview. It seemed that her mindset in conversations with non-native Japanese speakers was based on what she experienced as a non-native English speaker.

In quote 8 , Iwata also referred to her interlocutors' Japanese proficiency. There is extensive research on how native versus non-native Japanese speakers use polite style and plain style in different contexts. Kato (2006) revealed that native and non-native speakers share the norm of using "polite style in conversations of first encounters". Therefore, if native Japanese speakers use plain style from the beginning, as mentioned in quote 8, non-native speakers could get confused by the discrepancy between what they learned in their Japanese classes and how interlocutors outside the classroom actually express themselves. In other words, it could be claimed that even if Iwata wants to foster an interlocutor's Japanese proficiency, such behavior could actually work to its detriment with regard to acquiring the sociolinguistic norms of Japanese.

Although their specific mindsets were not put into words, Itai and Ichimaru, who likewise have much experience as non-native speakers of English, expressed that they care about the development of their interlocutors' lan guage skills.

\subsubsection{Wanting to Continue the Conversation}

Some native speakers reported their desire to continue conversations with non-native speakers. Related linguistic behaviours mentioned in interviews were overlooking errors, choosing comfortable topics, and asking many questions. With these mindsets, native speakers play the roles of language hosts in conversations with non-native speakers, who accordingly act as language guests. What Komoto expressed in quote 9 is in fact contradictory to what was described by Iwata in quote 6.

9) I often used to correct their mistakes, but recently not so much. It might make them unwilling to speak.

(from Komoto)

Komoto reported that he stopped correcting mistakes after he noticed that corrections could make non-native speak- 
ers unwilling to speak. He cited the reason for his recent behavior as because he wanted to engage in conversation with non-native speakers as long as possible without causing them stress. From the perspective of JLF, it could be argued that correcting mistakes should be avoided in order for there to be an equal relationship between native speakers and non-native speakers. However, at the same time, there are non-native speakers who are willing to have their mistakes corrected and to improve their language skills. Although the matter should be discussed further, one could argue that the best general principle is for native speakers to be flexible with regard to if and when to correct mistakes.

The next quote below concerns topics Iwata chose in conversations with non-native speakers.

10) When I talk with beginners, I choose familiar topics and ask what happened, not what they think.

(from Iwata)

Iwata raised some examples of questions which she often asks non-native speakers with low Japanese proficiency, including "What did you do yesterday?" and "What did you eat this morning?" Such specific questions are thought to be easier to answer than abstract questions, such as "What do you think about the news?" Similar mindsets were heard from other participants.

As for the desire to continue conversations, no factors influencing participants' mindsets were explicitly mentioned in the interviews.

\subsection{Three Factors Influencing Mindsets}

As a result of the semi-structured interviews described above, we found three factors that influence the mindsets of native speakers: experience interacting with non-native speakers, experience as non-native English speakers, and experience taking Japanese language teaching coursework.

The first two factors were mentioned in the category - taking care to speak intelligibly. Because non-native speakers primarily learn Japanese from Japanese language teachers, it seems reasonable that native speakers with experience taking Japanese language teaching coursework are confident of their ability to adjust their vocabulary according to their interlocutors. Although most of the interviewees said they can adjust their vocabulary, those with experience taking Japanese language teaching coursework and those without it could adjust in a different way.

The third factor, experience as a non-native English speaker, was only explicitly mentioned in discussions of the category - wanting to improve their interlocutors' Japanese language skills. Because three native speakers with considerable experience as non-native speakers studied abroad as international students in high school, it is possible they see elements of themselves as students and learners in non-native Japanese speakers. Ichimaru and Iwata showed their envisioned role as a supporter as below.

11) Every international student is like a big child.

(from Ichimaru)

12) In order for them to grow up, I do...

(from Iwata)

When asked the reason for her answer in quote 11, Ichimaru expressed that she thinks the experience with her host mother in America has greatly influenced the way she interacts with non-native speakers. Moreover, the three individuals with more experience had clear ideas of how to talk and demonstrated them very confidently in the interviews. They often used confident and assertive phrases, such as "I always do..." and "Unlike other native speakers, I do..." In addition, their attitudes seemed to be very supportive yet fixed at the same time. They basically assigned non-native speakers of Japanese the role of Japanese learners who are weaker than native speakers in their conversation skills yet want to learn 
Japanese nonetheless.

On the other hand, the other participants, who had no experience as non-native speakers of any language, expressed few indisputably clear ideas and lacked confidence when expressing them even though some of them have experience taking Japanese language teaching coursework. In the interviews, they often answered questions with lots of caveats, such as "I'm not sure if it's OK, but....", and "This is not what I always do, but..." However, because they were not confident, they seemed to be more flexible depending on the situation and interlocutor in questions than those interviewees with much experience as non-native speakers. Below are quotes from native Japanese speakers without much experience as non-native speakers of a language.

13) Only when I'm a tutor do I try to speak intelligibly.

(from Kaji)

14) If he seems confident with his Japanese, I speak with no adjustment.

(from Komoto)

Because there are many kinds of non-native speakers with different characteristics, native speakers should be flexible and adapt to each situation with a non-native speaker individually.

\section{Conclusion}

The purpose of this paper was to illustrate the mindsets of native speakers when interacting in conversations with non-native speakers and to reveal factors that influence them. The application of follow-up interviews as the research method allowed differences in those mindsets to be revealed. Mindsets mentioned in interviews were categorized into three groups - taking care to speak clearly, wanting to improve their interlocutors' Japanese language skills, and wanting to continue the conversation. Presenting actual narratives within each category should be valuable for future research. Moreover, three factors that seem to influence those mindsets were presented-experience interacting with non-native speakers, experience as non-native English speakers, and experience taking Japanese language teaching coursework.

However, the possible gap between what participants said they do and what they actually do needs to be considered. In addition, the result cannot be generalized due to the small sample size. Nonetheless, the results of this research make a contribution to discussions about JLF and how native Japanese speakers can learn it.

\section{References}

Brown, P., \& Levinson, S. C. (1987). Politeness: Some Universals in Language Usage. Cambridge University Press: Cambridge, UK.

Ferguson, C. A. (1981). "Foreigner Talk" as the Name of a Simplified Register. International Journal of the Sociology of Language, 28, 9-18.

Kato, Y. (2006). Sociolinguistic Norms about Speech Styles and Topic in Contact Situation. Bulletin of International Student Education Center Tokai University, 26, 1-17.

Milroy, L., \& Gordon, M. (2003). Sociolinguistics: Method and Interpretation. Blackwell Publishing: Oxford, UK.

Ministry of Internal Affairs and Communications (2006). Research Group Concerning the Promotion of Multicultural Coexistence: Towards the Promotion of Multicultural Coexistence in Local Communities. Available at: http://www.soumu.go.jp/kokusai/pdf/sonota_b5.pdf. (Last Accessed: 17 December 2017).

Miyamoto, C. Y. (2008). Consequences of Shifting Styles in Japanese: L2 Style-Shifting and L1 Listeners' Attitudes. In Melissa Bowles, Rebecca Foote, Silvia Perpiñán, and Rakesh Bhatt (eds), Selected Proceedings of the 2007 Second Language Research Forum. Cascadilla Proceedings Project: Somerville, USA, 131-143.

Okazaki, H. (2002). Content Based Japanese Language Teaching: from the perspective of Japanese Language Teaching in a Multilingual and Multicultural Society, In Reports of Grants-in-Aid for Scientific Research: Theory Construction for Teacher development in Japanese language teacher training program based on the model of reflective teaching, 322-339. Available at: http://www.dc.ocha.ac.jp/comparative-cultures/jle/Okazaki/naiyoo-juushi.html. (Last Accessed: 8 March 2018).

Okazaki, T. (2000). Japanese Language Education: Towards Multilingual and Multicultural Symbiosis In Mackie, V., Skoutarides, A. and 
A.Tokita (eds), Japanese studies: communities, cultures, critiqes Volume four: New directions in Japanese Linguistics. Monash Asia Institute: Clayton, Australia, 11-23.

Sakamoto, T., Misao, K., Machiko, H., Akie, K., Midori, I., \& Chieko, H. (1989). Learners' Reaction to Japanese Foreigner Talk. Journal of Japanese Language Teaching, 69, 121-146.

Tsuda, S. (2003). Interpersonal Functions of the Polite Forms Desu/Masu in Japanese Conversations. Intercultural Communication Studies XIX, 3, 81-89. 